\title{
Security needs among patients referred for high secure care in Broadmoor Hospital England
}

\author{
Hannah Kate Williams, Madhri Senanayke, Callum C. Ross, Rob Bates and Mary Davoren
}

\section{Background}

Security needs among patients referred to forensic mental health services have rarely been systematically studied.

\section{Aims}

To ascertain security needs among patients referred to a high secure hospital, Broadmoor High Secure Hospital, England. We also aimed to compare the security needs for those referred to mental illness services with those referred to personality disorder services in the hospital.

\section{Method}

A retrospective complete cohort study of all referrals to Broadmoor Hospital over a 2-year period was conducted. All referred patients $(n=204)$ were assessed for need for high secure care by two Broadmoor clinicians. The final decision on need for admission was taken by a multidisciplinary admission panel. Independent of the panel, researchers rated need for security using the DUNDRUM-1 triage security scale.

\section{Results}

Those admitted to Broadmoor Hospital had higher triage security scores than those declined ( $F=4.209$, d.f. $=1, P=0.042$ ).

Referrals to the personality disorder pathway had higher security needs than those referred to the mental illness pathway high secure service $(F=6.9835$, d.f. $=1, P=0.0089)$. Overall security needs among referrals to Broadmoor were extremely high, both by comparison with previous needs identified in UK medium secure services and international medium and high secure services.

\section{Conclusions}

High secure patient cohorts represent a uniquely vulnerable group within mental health services, with extremely high security needs identified in this study. This has significant implications for services given the high levels of resources needed to provide therapeutically safe and secure care and treatment to this group.

\section{Keywords}

Forensic psychiatry; therapeutic security; needs assessment; high security; risk assessment.

\section{Copyright and usage}

(c) The Author(s) 2020. Published by Cambridge University Press on behalf of the Royal College of Psychiatrists. This is an Open Access article, distributed under the terms of the Creative Commons Attribution-NonCommercial-NoDerivatives licence (http://creativecommons.org/licenses/by-nc-nd/4.0/), which permits non-commercial re-use, distribution, and reproduction in any medium, provided the original work is unaltered and is properly cited. The written permission of Cambridge University Press must be obtained for commercial re-use or in order to create a derivative work.

\section{Admission criteria for high secure hospitals}

Secure forensic services in England provide care and treatment to mentally disordered offenders at high, medium and low levels of therapeutic security. ${ }^{1,2}$ Admission criteria for high secure hospitals have rarely been studied. Patients admitted to these secure units, particularly at the higher levels of security, typically have very complex needs including treatment-resistant mental illness, personality disorder, neurocognitive diagnoses and substance misuse. ${ }^{3}$ There are also high rates of comorbidity of the above disorders seen among this very vulnerable group. ${ }^{3}$ The majority of secure admission beds are in medium- and low-security hospital units, with only a small number reserved for high secure care. ${ }^{1,2}$ High secure care in England is provided at three hospitals, Broadmoor serving London and the South of England, Ashworth Hospital serving Merseyside and the West and Rampton High Secure Hospital, which serves the North of England but also provides the national high secure services for women and for those with intellectual disability.

Admission to high secure services in England requires careful assessment and consideration. To admit a patient to a higher level of therapeutic security than absolutely necessary is a human rights issue as the individual may be subject to unnecessary restriction. This also has resource implications as high secure forensic admission beds are scarce and expensive. ${ }^{4,5}$ Admitting patients to too low a level of therapeutic security places fellow patients and staff at risk. ${ }^{5}$ It also limits the ability of therapists to safely challenge patients, which is a key component of therapeutic security, as appropriate challenge is inherent in all effective therapy. Therefore, careful assessment of the security needs of those referred for high secure care is essential for safe and effective running of mental health services in any jurisdiction. We identified only one study to date that systematically examined admission processes for high security hospitals. ${ }^{6}$

\section{Background}

In the early 1990s the National Health Service (NHS) England completed a large scale evaluation of the mental health and security needs of those who were, at that time, detained in conditions of high therapeutic security. ${ }^{7}$ A significant cohort of individuals in high secure settings who could have been managed at lower levels of therapeutic security were identified. This led to the development of additional medium secure units across England and large numbers of patients were appropriately transferred to these units. $^{3}$ At present in the three high secure hospitals, there is much oversight of those admitted to high secure services, but also clinicians are expected to frequently review the ongoing security needs of in-patients with a view to transferring people out to medium secure units as soon as it is safe to do so. As a result, the high secure services in England now work with a smaller number of more unwell, more acutely disturbed individuals with much higher security needs than in the past.

\section{Needs assessment tool for secure care}

The DUNDRUM-1 toolkit is a set of structured professional judgement instruments designed to assess a patient's need for secure 
care. ${ }^{8}$ It is a needs assessment, not a violence risk assessment, although history of violence clearly plays a role in any such assessment. The tool consists of five parts, the DUNDRUM-1 triage security scale and the DUNDRUM-2 triage urgency scale are designed to assess the level of security a patient should be admitted to and the urgency of need for admission, respectively. ${ }^{8-10}$ The DUNDRUM3 programme completion scale and the DUNDRUM-4 recovery scale are dynamic scales designed to assess a patient's current readiness to move to a less secure setting, for example transfer from high secure care to medium secure care, or medium secure care to low security or to the community. ${ }^{8,11,12}$ The fifth scale is the self-rated DUNDRUM scale that is designed to allow a patient to self-rate their own readiness to move to a less secure setting, i.e. to rate their own forensic recovery. ${ }^{8,13}$ It is a mirror image of the programme completion and recovery scales. The DUNDRUM tools have been validated in forensic mental health hospital settings and prison settings in multiple jurisdictions and have excellent psychometric properties. ${ }^{9}{ }^{14-17}$ The DUNDRUM-1 triage security scale has been shown to have good internal consistency (Cronbach's alpha 0.95 in a Dundrum sample validation and 0.77 in an international validation study) and good interrater reliability. ${ }^{9,10,15-19}$ Interrater reliability is better following training. ${ }^{17}$

\section{Objectives}

The aim of our study was to analyse the security needs among referrals to the admission panel at Broadmoor High Secure Hospital over a 2-year period. We also aimed to ascertain if there were differences between referrals to the mental illness pathway and the personality disorder pathway, in terms of security needs or urgency of need for admission to hospital.

\section{Method}

\section{Study design}

This was a retrospective cohort study comprising a complete cohort of all those referred for admission to Broadmoor Hospital from prisons or medium secure hospitals over a 2-year period, from 2015 to 2017. This comprised a total of 204 referrals. One patient transferred into Broadmoor from another high security hospital during the period of the study and was excluded.

All referrals to Broadmoor Hospital come with a request for admission from a psychiatrist detailing in a referral letter the reasons why high secure admission is being requested. Once a referral is received the patient will be reviewed by a consultant forensic psychiatrist or specialist registrar in forensic psychiatry from Broadmoor Hospital and independently by a forensic mental health social worker. Both professionals will then produce independent reports, recommending that admission is offered or declined. The two Broadmoor reports, together with the original request for admission, are then submitted to the Broadmoor admission panel, which is a multidisciplinary group led by a consultant forensic psychiatrist. The group will then take a view on whether admission is offered or declined. The most common reason the group would decline admission is that the view of the panel is that the patient does not meet the security needs that require a high secure admission and could be managed at a medium secure level.

Independently, two post-membership doctors in forensic psychiatry (H.K.W. and M.S.) completed the DUNDRUM-1 triage security and DUNDRUM-2 triage urgency scales on all 204 referrals for admission during the period of the study. The doctors were supervised by a consultant forensic psychiatrist and author of the DUNDRUM tool (M.D.). The researchers completing the DUNDRUM tool had only the information that was available to the Broadmoor admission panel team. The researchers were masked to the outcome of, or discussions at the Broadmoor admission panel and did not attend the panel for any of the discussions during this period. The clinicians on the admission panel were masked to the research ratings. The research scores did not in any way have an impact on patient care or admission decision-making by the panel of clinicians.

Demographic data, data pertaining to diagnosis and scores on the DUNDRUM-1 triage security scale and the DUNDRUM-2 triage urgency scale were gathered. Subsequent to the completion of the ratings, data pertaining to the admission outcomes were also gathered via hospital medical records. Data were analysed using the statistical package for the social sciences (SPSS-21).

\section{Setting}

The study was set in Broadmoor High Secure Hospital, Berkshire, England. Broadmoor is one of three high security hospitals in England, providing care and treatment to mentally disordered offenders who meet criteria for detention under the Mental Health Act and pose a grave and immediate risk to the public because of 'dangerous and violent criminal propensities'. ${ }^{20}$ The majority of mentally disordered offenders who require secure forensic hospital admissions in England are offered care and treatment in conditions of medium or low therapeutic security. Offering care and treatment at the lowest level of security appropriate to a patients' needs, or 'care in the least restrictive setting' is a key principle of the UK NHS. ${ }^{21}$ A total of over 7000 secure mental health beds are available in England, however, the majority of these are at a low and medium secure level with only 795 of these beds being high. Broadmoor provides 200 high secure beds for London and the South of England, a catchment area population of over 24 million. Therefore, those patients admitted to high secure care who cannot be safely managed in lower levels of security comprise a very small, highly selected group.

\section{Patients}

All referrals from medium secure hospitals or prisons to Broadmoor Hospital, for potential admission, between 2015 and 2017 were included in the study. Cases were ascertained from the admissions panel register to ensure a whole cohort with no bias. All were men and over 18 years, as Broadmoor does not admit women or children. Those referred were included regardless of whether they were referred for admission to the mental illness or personality disorder pathways and regardless of the source of admission (prison, medium or low secure hospital or in rare cases court referrals).

\section{Ethics}

This study was approved as a service evaluation study by the Broadmoor Hospital Audit and Service evaluation committee. The aim of the study was to evaluate the functioning and decisionmaking of the hospital admissions panel. Patient data was anonymised and no patient-identifiable data used. The decisionmaking of the panel was observed only, the research did not in any way affect decision-making regarding admission or the care and treatment of any patient. Informed consent was therefore not sought from the individual patients referred to the hospital during the period of the study. The authors assert that this work complies with the Helsinki declaration of 1975, updated in 2008.

\section{Statistical methods}

We investigated the associations between scores on the DUNDRUM-1 triage security scale and need for admission as 


\begin{tabular}{|c|c|c|c|c|}
\hline & $n$ & Security needs: DUNDRUM-1 score, ${ }^{a}$ mean & s.d. & ANOVA, $F$ (d.f.) $P$ \\
\hline \multicolumn{5}{|l|}{ Referrals to Broadmoor Hospital } \\
\hline Referred from: & & & & $25.276(1)<0.001$ \\
\hline Prison & 119 & 3.5938 & 0.32777 & \\
\hline Medium secure hospitals & 85 & 3.2667 & 0.3216 & \\
\hline Pathway referred to: & & & & 6.9835 (1) 0.0089 \\
\hline Mental illness pathway & 144 & 3.4059 & 0.39603 & \\
\hline Personality disorder pathway & 60 & 3.5574 & 0.32042 & \\
\hline \multicolumn{5}{|l|}{ Admission decisions at Broadmoor Hospital } \\
\hline Final outcome - decision of the Broadmoor admission panel & & & & 4.209 (1) 0.042 \\
\hline Admitted to Broadmoor & 111 & 3.4014 & 0.38845 & \\
\hline Not offered admission to Broadmoor & 93 & 3.3323 & 0.36735 & \\
\hline Forensic psychiatrist opinion & & & & $22.833(1)<0.001$ \\
\hline Admission recommended & 99 & 3.5825 & 0.30742 & \\
\hline Admission not recommended & 82 & 3.3388 & 0.37887 & \\
\hline Forensic social worker opinion & & & & $16.213(1)<0.001$ \\
\hline Admission recommended & 100 & 3.5533 & 0.30088 & \\
\hline Admission not recommended & 71 & 3.3318 & 0.41891 & \\
\hline
\end{tabular}

determined by (a) the opinion of the assessing high secure consultant psychiatrist, (b) the assessing high secure forensic social worker and (c) whether or not the patient was offered an admission bed by the high secure admission panel at Broadmoor Hospital. We compared the mean security needs between those referred from prison and medium secure hospital settings and also between the groups referred to the mental illness and personality disorder pathways. Mean scores on the DUNDRUM-1 security scale were compared using ANOVA, a 5\% significance level was adopted for the analysis and SPSS version 21 was used throughout.

\section{Results}

A total of 204 individual referrals were received by Broadmoor Hospital during the 2-year period 2015-2017 inclusive. All were men and the referrals came from prison $(n=119)$ and medium secure hospitals $(n=85)$.

The mean age at time of referral was slightly higher among those referred from other hospitals; 34.22 years (s.d. $=9.5$ ) from medium secure unit settings and 33.98 years $($ s.d. $=11.5)$ from prison settings, but this did not reach statistical significance $(P=0.154)$. Those referred to the personality disorder pathway (mean 36.89 years, s.d. $=10.7, n=60$ ) were older than those referred to the mental illness pathway $(33.02$ years, s.d. $=10.65, n=144)$ (ANOVA $F=5.028$, d.f. $=1, P=0.026$ ).

The majority of cases (54.1\%) had an established diagnosis of schizophrenia at the time of referral, $15.1 \%$ had a diagnosis of personality disorder established and $26.8 \%$ were referred with an unclear diagnosis, the remainder being other diagnoses. Diagnostic uncertainty was more common among those referred from prison referrals (41.2\%) compared with medium secure unit hospital referrals (7.1\%), for obvious reasons.

We found that overall the group of patients offered admission to Broadmoor Hospital by the Broadmoor admission panel $(n=111)$ had significantly higher mean scores on the DUNDRUM-1 triage security scale than those declined $(n=93)$ by the panel (ANOVA $F=4.209, P=0.042$ ) (Table 1). We found that those referred from prison had higher security needs than those referred from medium secure forensic hospital settings, although the security needs of all those referred, including those declined for admission by the Broadmoor admission panel were very high.

All referrals to Broadmoor, as mentioned above, are seen for independent pre-admission reports by a consultant forensic psychiatrist or specialist registrar in forensic psychiatry (under consultant supervision) and subsequently by a social worker from the high secure hospital. Those recommended for admission by the assessing forensic psychiatrist had higher mean DUNDRUM-1 security scores compared with the group not recommended for admission by the doctors (ANOVA $F=22.833$, d.f. $=1, P<0.001$ ), and a similar finding was found in relation to the social worker pre-admission assessments (ANOVA $F=16.213$, d.f. $=1, P<$ 0.001) (Table 1).

\section{Comparison of referrals to the personality disorder and mental illness pathways}

Although all referrals to Broadmoor Hospital had very high security needs as measured on the DUNDRUM-1 triage security scale, the security needs among those referred to the personality disorder pathway at Broadmoor were higher than the mean security needs scores of those referred to the mental illness pathway at Broadmoor (ANOVA $F=6.9835$, d.f. $=1, P=0.0089$ ). An item-tooutcome analysis was completed for the DUNDRUM-1 security needs items. We found that on all but two of the items on the DUNDRUM-1 triage security scale, those referred to the personality disorder pathway had higher mean scores than those referred to the mental illness pathway (the exceptions being 'seriousness of previous violence' and 'victim sensitivity and public confidence'). We found no significant difference in terms of urgency of need for admission between those referred to the personality disorder pathway and those referred to the mental illness pathway (ANOVA $F=0.304$, d.f. $=1, P=0.582$ ).

\section{Discussion}

Triaging patients to the appropriate level of therapeutic security is one of the most important decisions for any forensic mental health service. ${ }^{9}$ The use of structured professional judgement instruments can assist this process as unstructured judgement is prone to error and inconsistencies. In this study we found the scores on the DUNDRUM tool were closely aligned to the decisions of both the Broadmoor admission panel and the assessing clinicians. ${ }^{9,10,15}$ This demonstrated the strong clinical relevance of the tool. The DUNDRUM tool is designed to support clinical decision-making regarding triaging admissions, but it does not replace clinical decision-making. ${ }^{8}$ The aim of the triage tool is to improve the reliability and transparency of decision-making regarding the 
need for therapeutic security, to allow the hospital and clinicians to explain decisions to patients, commissioners and legal bodies when needed. ${ }^{8}$ It ensures that all the necessary factors are considered in the decision-making process, however, the final decision remains with the clinician.

This study demonstrated very high security needs among the group of patients referred for high secure care to Broadmoor Hospital, in keeping with the nature and purpose of high secure services in England. Previous studies using the DUNDRUM tool in other jurisdictions have demonstrated the security needs of referrals to and admissions into other services. We found the published security needs of referrals to a London medium secure service (The John Howard Centre, Hackney) were lower than those referred to Broadmoor, those admitted to Broadmoor and those declined for Broadmoor. ${ }^{15}$ The outcomes are unclear for the group whose security needs are not high enough to merit high security hospitals, but exceed those of medium secure units. This may represent a potential gap in service provision.

Comparing the security needs of those referred to and admitted to Broadmoor with admissions in other countries using previously published studies using the DUNDRUM-1 triage security scale, we found that the security needs of Broadmoor referrals were higher than those referred to forensic mental health services in Ireland, ${ }^{9,10}$ the Netherlands TBS (Terbeschikkingstelling) service, which offers medium secure hospital admissions to those at the end of prison sentences who have mental disorder, ${ }^{22}$ Netherlands long-stay high secure service, ${ }^{22}$ Belgian forensic services ${ }^{17,23,24}$ and Australian forensic services. ${ }^{16}$ In fact, no study using the DUNDRUM-1 triage security tool published to date has found higher security needs among any hospital or prison group than the Broadmoor referrals. This is a strength of this methodology using a reliable, internationally validated tool with strong psychometric properties can allow international comparisons of such groups.

\section{Limitations}

The main limitation of the study is that it is retrospective in nature. However, this methodology allowed a large number of referrals to be reviewed and rated by the researchers in a relatively timely manner. A whole cohort was assessed so that no bias was introduced. A second limitation is that the group only includes men, as Broadmoor only admits male patients. The study only included one of the three high security hospitals in England, and therefore the catchment area encompassed the South of England only. It is unclear if the patterns of very high security needs were specific to the catchment area covering the London Metropolitan area or would hold in the North and West of England. This question would merit a future study also.

\section{Interpretation}

Broadmoor Hospital offers care and treatment to a uniquely vulnerable group of patients with very high security needs. The patient group referred to the personality disorder pathway in the high secure hospital had particularly complex security needs, however, it remains unclear why that was the case and this would merit further research. Although the differences in mean scores between the patient groups may not appear large, the scores on the DUNDRUM tool are organised in units of meaningful change, representing the different levels of therapeutic security available in international forensic hospital settings, therefore the differences between the groups in terms of security needs are both statistically and clinically significant.

The very high security needs seen here among the Broadmoor group may in part explain the need for higher staff to patient ratio's and why one might expect a higher need for restrictive practices to prevent violence among the high security patient group, compared with the groups at medium and low therapeutic security. The use of any restrictive practice, for example seclusion or longterm seclusion, must always be as an absolute last resort to prevent serious and immediate violence. The greatest predictor of future violence is past violence. ${ }^{25}$ The DUNDRUM tool rates baseline security needs, such as seriousness of previous violence, violence not exclusive to the context of major mental illness and violence that is particularly complex for example with sadistic features or other unusual aspects. ${ }^{8}$ The finding that the group admitted to Broadmoor scored significantly higher on this tool, compared with medium or low secure patient groups, is in keeping with a group that are likely to present with complex challenging behaviour as in-patients.

Specialised therapeutically secure psychiatric services within high secure settings such as Broadmoor are an essential resource, given the significant differences seen between those admitted to Broadmoor and not admitted, and those admitted to mental illness and personality disorder services in this study. High secure hospitals are admitting a different group compared with medium and low secure hospitals. This may, at least in part explain the need for greater levels of physical, procedural and most importantly relational security seen in the English high secure hospital services. These results are likely to be generalisable to other high security hospitals in England and in other jurisdictions, and this may be an area of future collaborative research.

Hannah Kate Williams, MBChB, MSC, BSC(Hons), MRCPSych, South West London and St George's NHS Trust, UK' Madhri Senanayke MB, MRCPSych Broadmoor Hospital and West London NHS Trust, UK; Callum C. Ross, MB, MRCPsych, Broadmoor Hospital and West London NHS Trust, UK; Rob Bates, MB, MRCPsych, Broadmoor Hospital and West London NHS Trust, UK; Mary Davoren (D), MB, BCh BAO, MD, MRCPsych, Broadmoor Hospital and West London NHS Trust, UK

Correspondence: Mary Davoren. Email: davorem@tcd.ie

First received 23 Feb 2020, final revision 18 Apr 2020, accepted 20 Apr 2020

\section{Data availability}

Due to the uniquely sensitive nature of this data-set, access to data will only be provided on a strict case-by-case basis.

\section{Acknowledgements}

The authors would like to acknowledge the medical records department at Broadmoor Hospital for their support in completing this study.

\section{Author contributions}

M.D. designed the study and formulated the research question with C.C.R., H.K.W. and M.S completed the DUNDRUM-triage tool ratings. M.D. and H.K.W. analysed the data. All contributed to the authorship of the paper.

\section{Declaration of interest}

None.

ICMJE forms are in the supplementary material, available online at https://doi.org/10.1192/ bjo.2020.35.

\section{References}

1 Duke L H, Furtado V, Guo B, Vollm BA. Long-stay in forensic-psychiatric care in the UK. Soc Psychiatry Psychiatr Epidemiol 2018; 53: 313-21.

2. Rutherford M, Duggan S. Forensic Mental Health Services: Facts And Figures On Current Provision. Sainsbury Centre for Mental Health, 2007.

3 Coid J, Kahtan N, Gault S, Cook A, Jarman B. Medium secure forensic psychiatry services: comparison of seven English health regions. Br J Psychiatry 2001; 178: $55-61$. 
4 McCrone P. Paying the Price: The Cost of Mental Health Care in England to 2026. King's Fund, 2008.

5 Kennedy HG. Therapeutic uses of security: mapping forensic mental health services by stratifying risk. Adv Psychiatr Treat 2002; 8: 433-43.

6 Brown CS, Lloyd K. OPRISK: a structured checklist assessing security needs for mentally disordered offenders referred to high security psychiatric hospital. Crim Behav Ment Health 2008; 18: 190-202.

7 Office H, Health Do, Security S. Report of the Committee on Mentally Abnormal Offenders. HMSO, 1975.

8 Kennedy H, O'Neill C, Flynn G, Gill P, Davoren M. The DUNDRUM toolkit draft V1. 0.30. Trinity College Dublin, 2016.

9 Flynn G, O'Neill C, McInerney C, Kennedy HG. The DUNDRUM-1 structured professional judgment for triage to appropriate levels of therapeutic security: retrospective-cohort validation study. BMC Psychiatry 2011; 11: 43.

10 Flynn G, O'Neill C, Kennedy HG. DUNDRUM-2: prospective validation of a struc tured professional judgment instrument assessing priority for admission from the waiting list for a forensic mental health hospital. BMC Res Notes 2011; 4: 230 .

11 Davoren M, O'Dwyer S, Abidin Z, Naughton L, Gibbons O, Doyle E, et al. Prospective in-patient cohort study of moves between levels of therapeutic security: the DUNDRUM-1 triage security, DUNDRUM-3 programme completion and DUNDRUM-4 recovery scales and the HCR-20. BMC Psychiatry 2012; 12: 80

12 Davoren M, Abidin Z, Naughton L, Gibbons O, Nulty A, Wright B, et al. Prospective study of factors influencing conditional discharge from a forensic hospital: the DUNDRUM-3 programme completion and DUNDRUM-4 recovery structured professional judgement instruments and risk. BMC Psychiatry 2013; 13: 185

13 Davoren M, Hennessy S, Conway C, Marrinan S, Gill P, Kennedy HG. Recovery and concordance in a secure forensic psychiatry hospital - the self rated DUNDRUM-3 programme completion and DUNDRUM-4 recovery scales. BMC Psychiatry 2015; 15: 61.
14 O'Dwyer S, Davoren M, Abidin Z, Doyle E, McDonnell K, Kennedy HG. The DUNDRUM Quartet: validation of structured professional judgement instruments DUNDRUM-3 assessment of programme completion and DUNDRUM-4 assessment of recovery in forensic mental health services. BMC Res Notes 2011; 4: 229.

15 Freestone M, Bull D, Brown R, Boast N, Blazey F, Gilluley P. Triage, decisionmaking and follow-up of patients referred to a UK forensic service: validation of the DUNDRUM toolkit. BMC Psychiatry 2015; 15: 239

16 Adams J, Thomas SD, Mackinnon T, Eggleton D. The risks, needs and stages of recovery of a complete forensic patient cohort in an Australian state. BMC Psychiatry 2018; 18: 35.

17 Habets $P$, Jeandarme I, Kennedy HG. Applicability of the DUNDRUM-1 in a forensic Belgium setting. J Forensic Pract 2019; 21: 85-94.

18 Jones RM, Patel K, Simpson AIF. Assessment of need for inpatient treatment for mental disorder among female prisoners: a cross-sectional study of provincially detained women in Ontario. BMC Psychiatry 2019; 19: 98.

19 Lawrence D, Davies TL, Bagshaw R, Hewlett P, Taylor P, Watt A. External validity and anchoring heuristics: application of DUNDRUM-1 to secure service gatekeeping in South Wales. BJPsych Bull 2018; 42: 10-8.

20 UK Government. National Health Service Act 2006: 2006 Part 1, Section 4(1). HMSO, 2006

21 Department of Health. Mental Health Act 1983: Code of Practice. HMSO, 2015.

22 Eckert M, Schel SHH, Kennedy HG, Bulten BH(E). Patient characteristics related to length of stay in Dutch Forensic Psychiatric Care. J Forensic Psychiatry Psychol 2017; 28: 863-80.

23 Jeandarme I, Habets P. Determining security need in forensic psychiatric patients: HoNOS-Secure and DUNDRUM-1. Tijdschr Psychiatr 2019; 61: 455-63.

24 Jeandarme I, Habets $P$, Kennedy $H$. Structured versus unstructured judgment: DUNDRUM-1 compared to court decisions. Int J LaW Psychiatry 2019; 64: 205-10.

25 Monaghan JSH. Violence and Mental Disorder: Developments in Risk Assessment. Univeristy of Chicago Press, 1994. 